EXTENDED REPORT

\title{
Autogenous temporalis fascia patch graft for porous polyethylene (Medpor) sphere orbital implant exposure
}

\author{
M S Sagoo, J M Olver
}

Br J Ophthalmol 2004;88:942-946. doi: 10.1136/bjo.2003.026823

See end of article for authors' affiliations

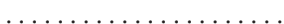

Correspondence to: Ms J M Olver, Ophthalmology Department, Charing Cross Hospital, Fulham Palace Road, London W6 8RF, UK.

Janeolver@aol.com

Accepted 27 October 2003

\begin{abstract}
Background: Temporalis fascia has been recommended for hydroxyapatite sphere exposure. The aim of this study was to identify potential risk factors for exposure of porous polyethylene (Medpor) sphere implants and evaluate the use of autogenous temporalis fascia as a patch graft for exposure.

Methods: A retrospective review of consecutive cases of porous polyethylene sphere orbital implant exposure.

Results: Five cases presented between May 2000 and October 2001 (three males, two females; mean age 44.5 years). Three had enucleation (two with primary implants) and two had evisceration (one with primary implant). Exposure occurred in one primary, two secondary, and two replacement implants. Orbital implant diameter was $20 \mathrm{~mm}$ in four cases and $16 \mathrm{~mm}$ in one case (contracted socket). The mean time from implantation to exposure was 23 months (range 0.7-42.6). Three patients had secondary motility peg placement before exposure. The average time from last procedure (sphere implant or peg insertion) to exposure was 3 months (range 0.7-12.6). Four patients required surgical intervention, of which three needed more than one procedure. Autogenous temporalis fascia grafting successfully closed the defect without re-exposure in three of these four patients. The grafts were left bare in three patients, with a mean time to conjunctivalise of 2.4 months (range 1.6-3.2).

Conclusions: Exposed porous polyethylene sphere implants were treated successfully with autogenous temporalis fascia graft in three of four patients. This technique is useful, the graft easy to harvest, and did not lead to prolonged socket inflammation, infection, or extrusion.
\end{abstract}

$\mathrm{P}$ orous spherical implants are in general use to replace volume after enucleation or evisceration, with the fitting of a prosthetic eye to give a good aesthetic result. ${ }^{1-4}$ These implants are biocompatible and become vascularised, preventing migration and extrusion. ${ }^{5}$ A motility peg can be fitted after 12-18 months, to increase the range of movement where there is poor prosthesis motility. ${ }^{6}$

The most common complication of porous spherical implants is exposure caused by breakdown of the covering layers $(0-35 \% \text { incidence })^{7-12}$ which may lead to extrusion. Implant position deep to posterior Tenon's, and covering technique (wrap/anterior patch/patch and cap with Vicryl mesh (Vicryl, Ethicon Ltd, Edinburgh, UK) or salvaged sclera), is important in reducing exposure. ${ }^{13-18}$

Hydroxyapatite spherical orbital implant exposure treated with temporalis fascia patch has been previously reported. ${ }^{7} 1020$ In this retrospective study we aimed to identify potential risk factors for exposure of porous polyethylene spherical implants and evaluate the use of temporalis fascia patch graft in managing the exposure.

\section{MATERIALS AND METHODS}

Consecutive adult patients with porous polyethylene (Medpor, Pores Surgical, Newnan, GA, USA) orbital implant exposure presenting to the Oculoplastic and Orbital Service between May 2000 and October 2001 were identified from the clinic database. A retrospective case note review of these consecutive cases was carried out. Patient demographics, the original aetiology, details of original and secondary surgical procedures, timing of exposure, possible risk factors, and details of further management were recorded.

Exposure was initially treated conservatively (topical antibiotics and steroid, prosthetic manipulation as necessary). If exposure persisted, surgical treatment was indicated, including use of autogenous temporalis fascia patch graft. If re-exposure occurred, then further surgery in the form of grafts, or other autogenous or exogenous material, was considered.

The deep temporalis fascia overlies the temporalis muscle and is easily accessible for harvest (fig 1A) A vertical scalp incision is made in line with the tragus of the ear and posterior to the superficial temporal artery. (fig 1B). The subcutaneous fat and superficial temporalis fascia are dissected to expose a large enough area of the silver coloured deep fascia (fig lC). A patch of deep fascia approximately 15$18 \mathrm{~mm}$ diameter is excised and placed in a pool of saline before placement. (fig lD). A peroperative example is shown in figure 2. Horizontal conjunctival relieving incisions are made adjacent to the exposed area. A pocket between the implant and Tenon's fascia is created into which the edge of the temporalis fascia graft is placed (fig $2 \mathrm{~B}$ ). Tenon's fascia and conjunctiva are closed over the graft when possible or sutured to its anterior surface and the graft left to conjunctivalise. (fig 2C).

\section{RESULTS}

Five patients with exposed porous polyethylene spherical implants were identified (see table 1). Three had been enucleated (one secondary and two replacement implants) and two eviscerated (one primary and one secondary implant).

Potential risk factors for exposure at the time of the placement of the sphere included the diameter of the implant (20 $\mathrm{mm}$ in $4 / 5$, one patient had a $16 \mathrm{~mm}$ implant placed in a contracted socket subsequent to retinoblastoma radiotherapy); peroperative orbital haemorrhage on secondary implant placement (one patient); and choice of anterior cover.

Exposure occurred at an average of 23 months after the implant had been placed (range 0.7-42.6, median 32 months). Three of the five patients had motility peg 


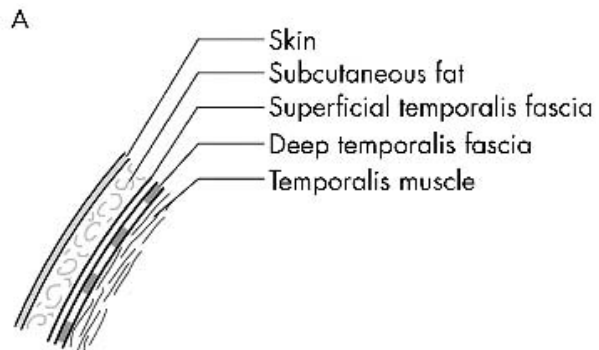

B Conjoint tendon

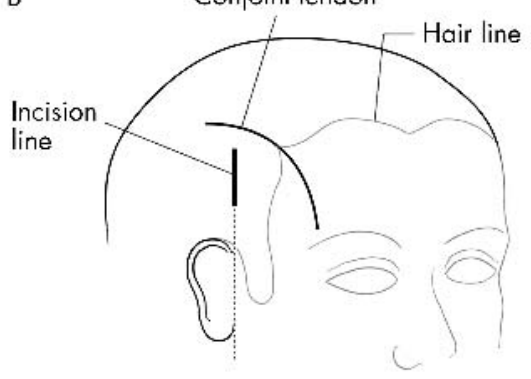

C

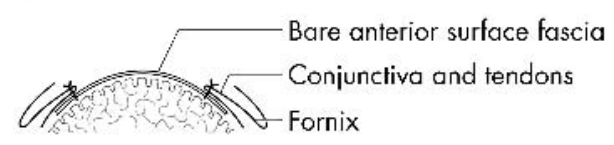

D

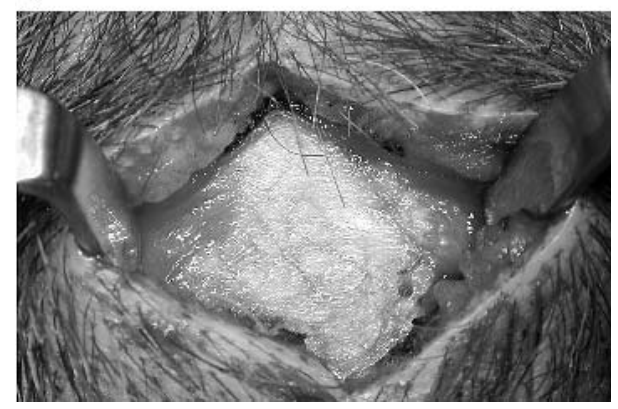

Figure 1 (A) Diagram showing layers of the scalp overlying the temporalis muscle. (B) Diagram showing incision for harvesting the deep temporalis fascia: the incision is made within the hair line, in a line from the tragus of the ear. (C) Peroperative view of deep temporalis fascia. (D) Cross section of the completed surgery-temporalis fascia is left to conjunctivalise, unless conjunctiva and Tenon's fascia can be advanced.

insertion as a secondary procedure before the implant became exposed. In order to allow adequate vascularisation, pegging was carried out at an average of 33 months after sphere implant placement (range 26-42 months). The average time from the last procedure (peg insertion or ball implant) to exposure was 13 weeks. Most cases of exposure were early (within six weeks), though there was one implant that became exposed 51 weeks after last procedure.

Exposure gave rise to peri-peg pyogenic granuloma in one patient but there were no cases of either granuloma formation or granuloma removal giving rise to exposure.

All patients were treated initially with topical antibiotics, supplemented in two patients with topical dexamethasone.
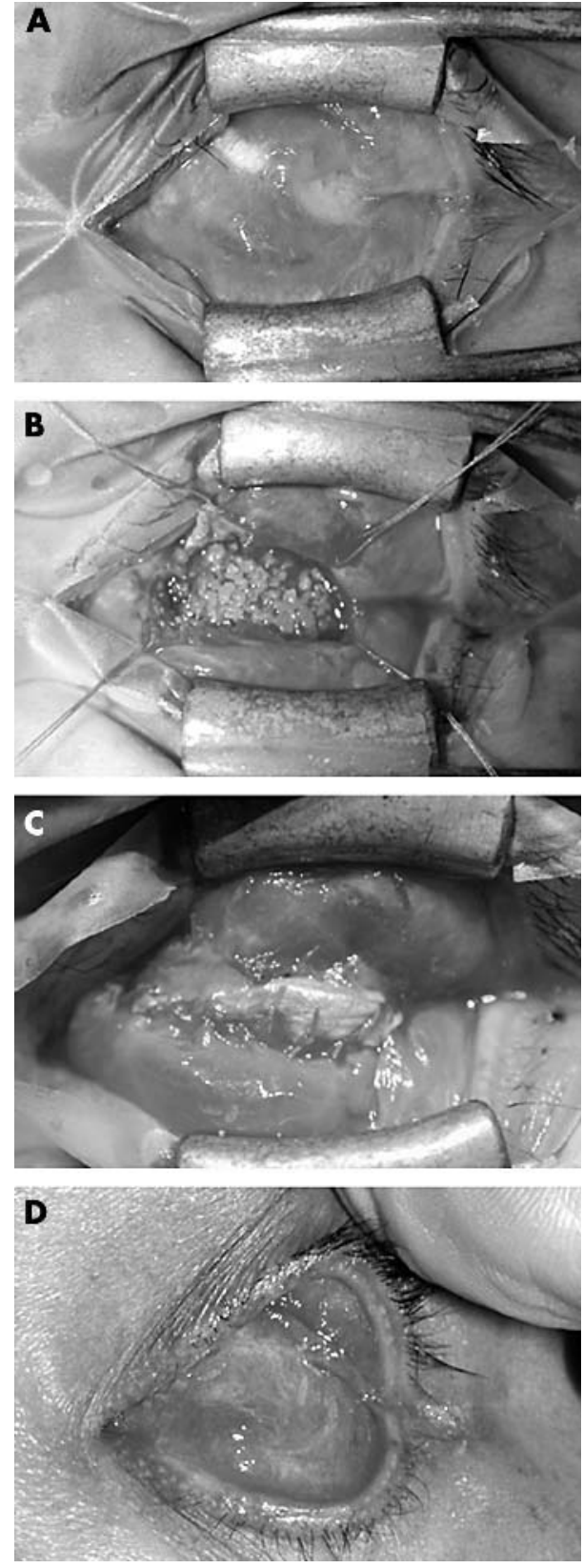

Figure 2 Clinical example: case 2. (A) Chronic exposed anterior surface of Medpor implant. (B) Creation of a pocket under the conjunctival/Tenon's edge, to take the temporalis fascia graft. (C) The conjunctiva is then sutured to the anterior edge of the graft, in this case, leaving an area of bare fascia. (D) Healed postoperative appearancethe area of bare temporalis fascia over the exposed Medpor has completely conjunctivalised.

One patient (case 3) healed well on conservative treatment alone (chloramphenicol and dexamethasone).

Four out of five patients required surgery and three needed more than one operation. The average time from implant exposure to first operation was 3 months. Trimming of the implant (case 5), resuturing of the conjunctiva (cases 4 and 5), granuloma excision (case 4), and hard palate and mucous membrane graft (case 5) were procedures that failed to control the exposed site before the use of temporalis fascia.

Four out of five patients in this series had autogenous temporalis fascia grafting at an average of 4.8 months after exposure first occurred. Tenon's capsule and conjunctiva were closed over the temporalis fascia in one implant only 
Table 1 Case review of Medpor sphere exposure: summary of results

\begin{tabular}{|c|c|c|c|c|c|c|c|}
\hline Case (age; sex) & $\begin{array}{l}\text { Original aetiology } \\
\text { and procedure }\end{array}$ & $\begin{array}{l}\text { Porous polyethy- } \\
\text { lene orbital } \\
\text { sphere implant }\end{array}$ & $\begin{array}{l}\text { Anterior cover } \\
\text { (in addition to } \\
\text { conjunctiva \& } \\
\text { Tenon's) }\end{array}$ & $\begin{array}{l}\text { Time to } 2^{\circ} \\
\text { motility peg } \\
\text { (months) }\end{array}$ & $\begin{array}{l}\text { Time from most } \\
\text { recent procedure } \\
\text { to implant } \\
\text { exposure (weeks) }\end{array}$ & $\begin{array}{l}\text { Size of } \\
\text { defect } \\
\text { (mm) }\end{array}$ & $\begin{array}{l}\text { Management for } \\
\text { complete healing }\end{array}$ \\
\hline 1 (59 years; F) & $\begin{array}{l}\text { Trauma; enucleation } \\
\text { and acrylic sphere }\end{array}$ & $\begin{array}{l}\text { Replacement, } \\
20 \mathrm{~mm}\end{array}$ & $\begin{array}{l}\text { Implant pseudo- } \\
\text { capsule }\end{array}$ & - & 6 & $8 \times 8$ & $\begin{array}{l}\text { Temporalis fascia, } \\
\text { then donor sclera then } \\
\text { buccal mucosa }\end{array}$ \\
\hline 2 (52 years; F) & $\begin{array}{l}\text { Trauma; enucleation } \\
\text { and glass sphere }\end{array}$ & $\begin{array}{l}\text { Replacement, } \\
20 \mathrm{~mm}\end{array}$ & None & - & 3 & $5 \times 7$ & Temporalis fascia \\
\hline 3 (30 years; $M)$ & $\begin{array}{l}\text { Tumour retinoblastoma; } \\
\text { enucleation }\end{array}$ & $\begin{array}{l}\text { Secondary, } \\
16 \mathrm{~mm}\end{array}$ & Prolene mesh & 32 & 1 & $5 \times 10$ & $\begin{array}{l}\text { Topical antibiotic/ } \\
\text { steroid }\end{array}$ \\
\hline 4 (41 years; $M)$ & $\begin{array}{l}\text { Retinal detachment } \\
\text { and PVR; evisceration }\end{array}$ & $\begin{array}{l}\text { Primary, } \\
20 \mathrm{~mm}\end{array}$ & $\begin{array}{l}\text { Cap and patch } \\
\text { autogenous } \\
\text { salvaged sclera }\end{array}$ & 26 & 51 & $6 \times 6$ & Temporalis fascia \\
\hline \multirow[t]{2}{*}{5 (40 years; $M)$} & Trauma; evisceration & $\begin{array}{l}\text { Secondary, } \\
20 \mathrm{~mm}\end{array}$ & $\begin{array}{l}\text { Cap and patch } \\
\text { autogenous } \\
\text { salvaged sclera }\end{array}$ & 42 & 3 & $4 \times 3.5$ & Temporalis fascia \\
\hline & & & & Mean $=33$ & Mean $=13$ & & \\
\hline
\end{tabular}

(case 5), as the remainder had a contracted socket, forniceal shortening, conjunctival scarring, or a combination of these.

Autogenous temporalis fascia graft successfully closed the defect without re-exposure in three out of four patients. The time to heal was an average of 2.4 months (range 1.6-3.2 months) and the mean follow up period after surgery was 16 months (range 8-24 months). Patients wore either a vaulted artificial eye or a conformer in the postoperative period (see fig 2D).

Implant re-exposure occurred in one patient following temporalis fascia graft, requiring donor scleral graft and subsequently a buccal mucosa graft. Although there had been conjunctivalisation of the temporalis fascia graft, further conjunctival inflammation and discharge led to re-exposure. Conjunctival microbiology showed no growth.

No patients had implant migration or extrusion and none developed orbital cellulites or required removal of the implant.

\section{DISCUSSION}

We describe the use of temporalis fascia grafts in the management of porous polyethylene (Medpor) sphere implants. Exposure rates in this type of implant vary from low incidence ${ }^{38}$ to $53 \%$ in retinoblastoma patients. ${ }^{12}$ Autogenous temporalis fascia grafts have been used in hydroxyapatite and silicone orbital implant exposure. ${ }^{2021}$ In this small case series of porous polyethylene spheres, temporalis fascia was used successfully in three of four patients who needed surgery, healing within 2.4 months.

Small areas of tissue breakdown can heal spontaneously. ${ }^{7}$ In this series, none healed spontaneously and one healed on topical therapy.

It is difficult to identify risk factors from this small case series, but potential candidates emerge in comparison with previous work. Preoperative risk factors for exposure included trauma as the aetiology of removal of the globe. ${ }^{8}$ One case had previous orbital radiotherapy, which may

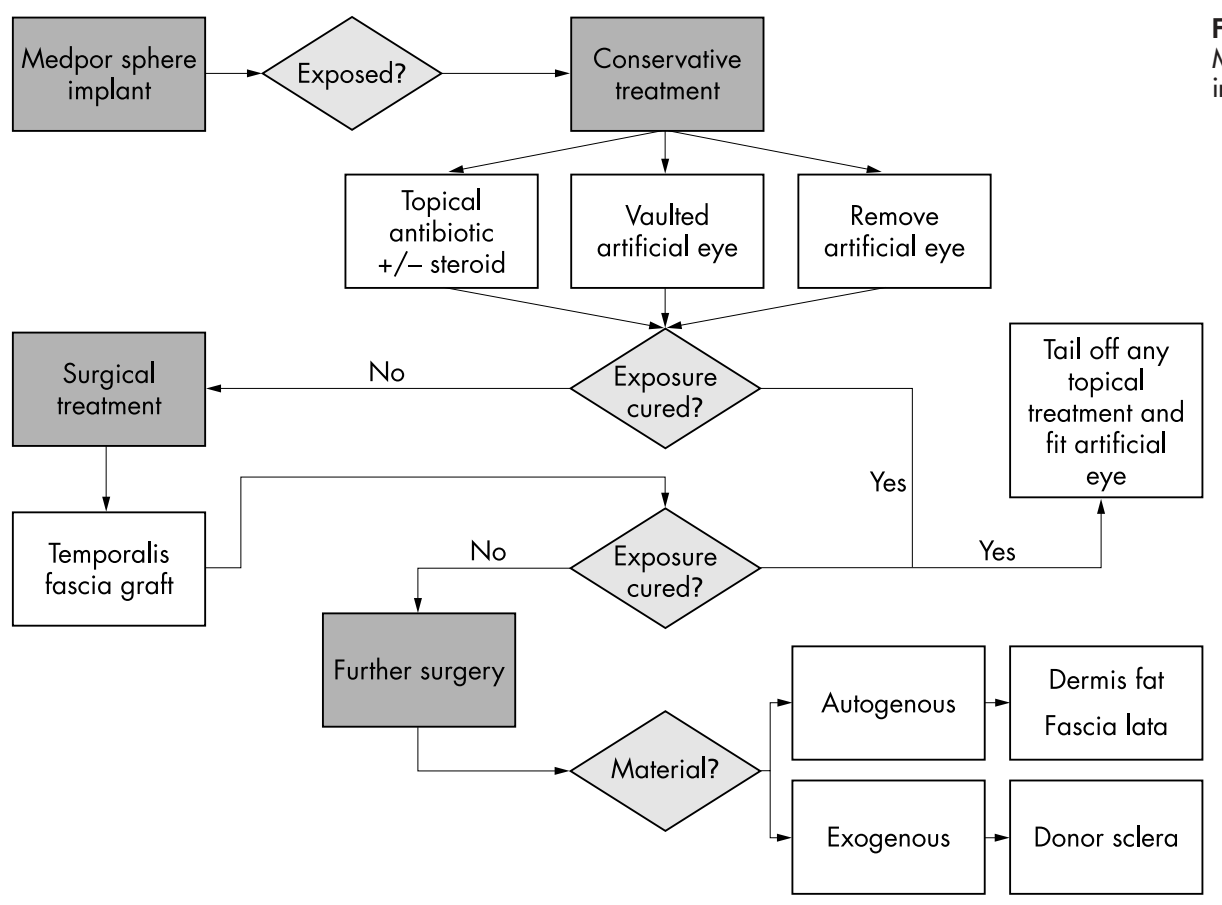

Figure 3 Treatment algorithm for Medpor (porous polyethylene) sphere implant exposure. 
predispose to tissue breakdown, though in other studies the relation of implant exposure to radiotherapy has not been proved..$^{12}$ Complications, including exposure, are more common following evisceration versus enucleation, ${ }^{8}$ probably dependent on technique.

Peroperative haemorrhage, the cover material used, and the relative size of the implant are likely peroperative risk factors. The cover material ranged from autogenous salvaged sclera to synthetic mesh to no cover. Complications are best avoided with good surgical technique. ${ }^{22}$ Various other implant cover materials have been recommended to reduce exposure rates, including a corneoscleral button, autogenous periosteum from the supraorbital rim, ${ }^{16}$ primary banked scleral patch graft, ${ }^{218}{ }^{19}$ homologous sclera, ${ }^{11}$ and an enucleation technique conserving the anterior globe with placement of the implant posterior to this. ${ }^{17}$ Mersilene mesh wrapping has led to higher exposure rates, possibly because of mechanical factors causing exposure ${ }^{12}$ and is no longer used by the authors.

Secondary motility peg insertion has not been reported to lead to hydroxyapatite implant exposure, although the peg extruded in $26 \%{ }^{6}$ In this study, motility pegs were inserted in three of five cases at least 26 months after sphere implant placement to allow for vascularisation. Two of the pegged implants exposed within the first month and one became exposed after almost a year. Without explanting the sphere for histological analysis the only indication of adequate vascularisation is bleeding during drilling of the sphere, which occurred in all cases where a peg was placed or the implant was trimmed before the temporalis fascia graft.

Prolonged postoperative non-granulomatous conjunctival inflammation was associated with exposure in one case. Postoperative granuloma formation did not cause exposure, but was a secondary healing response. In another series exposure occurred after the granulomatous inflammatory response was treated with intensive topical steroid and settled on discontinuation. ${ }^{16}$ Both granulomatous response and tissue breakdown have been reported. ${ }^{23}$

Based on this case series, we have developed a treatment algorithm for porous polyethylene implant exposure (fig 3), starting conservatively, using medical therapy and manipulation of the ocular prosthesis, and patching as necessary. Temporalis fascia patch graft is favoured for three reasons. Firstly, it is an easy graft to harvest from a surgical field that is in close proximity to the domain of the orbital surgeon and to many ophthalmologists performing superficial temporal artery biopsies. Secondly, the material is autogenous, reducing the risk of immunological reaction and of introducing infection. Other techniques for the management of porous sphere implant exposure fall into two main categories: those that use exogenous versus autogenous material. The latter group includes a modified Hughes type tarsoconjunctival flap graft, ${ }^{24}$ fascia lata patch grafts, ${ }^{132122}$ and dermis fat as a secondary implant. ${ }^{22}$ Exogenous scleral patch grafts carry the risk of transmission of slow virus infection. ${ }^{14}{ }^{15}$ Because of this risk of transmissible diseases, there has been debate on the merits of autogenous materials, with temporalis fascia patch graft being advocated as a primary procedure to prevent hydroxyapatite implant exposure ${ }^{25}$; similar approaches may yield lower exposure rates with porous polyethylene implants. Thirdly, extrusion of the implant or motility peg does occur with temporalis fascia grafts. Wiggs and Becker treated silicone orbital implant exposure with autogenous temporalis fascia, and found one of 11 cases required surgery for extrusion having developed pseudomonas conjunctivitis. ${ }^{21}$ In hydroxyapatite implants, Pelletier et al did not have any cases of infection or extrusion. ${ }^{20}$ Based on our experience of no implants extruding in an average follow up period of 16 months, all of these cases avoided explantation.
In this series one patient re-exposed and tissue breakdown continued even with a subsequent donor scleral cap and patch graft and then buccal mucosa graft. Histology of the original cover material (pseudo-capsule of an acrylic sphere) showed chronic inflammatory changes and if some degree of inflammation persisted, this may have led to repeated episodes of exposure.

Porous polyethylene implants exposure is not restricted to orbital sphere implants, and occurs in nasal, chin, malar, and ear reconstruction with shaped porous polyethylene. ${ }^{26}{ }^{27}$ Their management is similar, either with skin graft, free or pedicled flaps, or implant removal.

\section{CONCLUSION}

The use of an autologous temporalis fascia patch graft enables successful repair of porous polyethylene (Medpor) sphere implant exposure without leading to infection, extrusion, or explantation, and should be considered where conservative treatment is not curative.

\section{Authors' affiliations}

M S Sagoo, J M Olver, Oculoplastic and Orbital Service, Ophthalmology Department, Charing Cross Hospital, London, UK

Financial support: none.

Commercial interests: none.

This paper was presented at the European Society of Ophthalmic Plastic and Reconstructive Surgery in Munster, Germany, September 2002.

\section{REFERENCES}

1 Danz W Sr. Mobility implants: a review. Adv Ophthalmic Plast Reconstr Surg 1990;8:46-52

2 Shields CL, Shields JA, De Potter P, et al. Lack of complications of the hydroxyapatite orbital implant in 250 consecutive cases. Trans Am Ophthalmol Soc 1993;91:177-89.

3 Karesh JW, Dresner SC. High-density porous polyethylene (Medpor) as a successful anophthalmic socket implant. Ophthalmology 1994;101:1688-95, discussion 1695-6.

4 Fan JT, Robertson DM. Long-term follow-up of the Allen implant. 1967 to 1991. Ophthalmology 1995;102:510-16.

5 De Potter P, Duprez T, Cosnard G. Postcontrast magnetic resonance imaging assessment of porous polyethylene orbital implant (Medpor). Ophthalmology 2000; 107:1656-60

6 Edelstein C, Shields CL, De Potter P, et al. Complications of motility peg placement for the hydroxyapatite orbital implant. Ophthalmology 1997:104:1616-21.

7 Buettner H, Bartley GB. Tissue breakdown and exposure associated with orbital hydroxyapatite implants. Am J Ophthalmol 1992;1 13:669-73.

8 Remulla HD, Rubin PA, Shore JW, et al. Complications of porous spherical orbital implants. Ophthalmology 1995; 102:586-93.

9 McNab A. Hydroxyapatite orbital implants. Experience with 100 cases. Aust N Z J Ophthalmol 1995;23:117-23.

10 Oestreicher JH, Liu E, Berkowitz M. Complications of hydroxyapatite orbital implants. A review of 100 consecutive cases and a comparison of Dexon mesh (polyglycolic acid) with scleral wrapping. Ophthalmology 1997;104:324-9.

11 Van Acker E, De Potter P. Implant orbitaire en polyethylene poreux (Medpor). J Fr Ophtalmol 2001;24:1067-73.

12 Lee V, Subak-Sharpe I, Hungerford JL, et al. Exposure of primary orbital implants in postenucleation retinoblastoma patients. Ophthalmology 2000; 107:940-6

13 Levine MR. Extruding orbital implant: prevention and treatment. Ann Ophthalmol 1980;12:1384-6.

14 Fountain JA, Helveston EM. A long-term follow-up study of scleral grafting for exposed or extruded orbital implants. Am J Ophthalmol 1982;93:52-6.

15 Goldberg MF. A simplified scleral graft technique for covering an exposed orbital implant. Ophthalmic Surg 1988;19:206-11.

16 Beaver HA, Patrinely JR, Holds JB, et al. Periocular autografts in socket reconstruction. Ophthalmology 1996;103:1498-502.

17 Adenis JP, Rulfi JY, Robert PY. Evisceration selon la technique de la poupee russe ou du parachute. J Fr Ophtalmol 2001;24:887-92.

18 Inkster CF, Ng SG, Leatherbarrow B. Primary banked scleral patch graft in the prevention of exposure of hydroxyapatite orbital implants. Ophthalmology 2002;109:389-92.

19 Shields CL, Shields JA, De Potter P, et al. Problems with the hydroxyapatite orbital implant: experience with 250 consecutive cases. Br J Ophthalmol 1994;78:702-6.

20 Pelletier CR, Jordan DR, Gilberg SM. Use of temporalis fascia for exposed hydroxyapatite orbital implants. Ophthal Plast Reconstr Surg 1998; 14:198-203. 
21 Wiggs EO, Becker BB. Extrusion of enucleation implants: treatment with secondary implants and autogenous temporalis fascia or fascia lata patch grafts. Ophthalmic Surg 1992;23:472-6.

22 Oberfeld S, Levine MR. Diagnosis and treatment of complications of enucleation and orbital implant surgery. Adv Ophthalmic Plast Reconstr Surg 1990:8:107-17.

23 Christmas NJ, Gordon CD, Murray TG, et al. Intraorbital implants after enucleation and their complications: a 10-year review. Arch Ophthalmol $1998 ; 116: 1199-203$
24 Soparkar CNS, Patrinely JR. Tarsal patch-flap for orbital implant exposure. Ophth Plast Recontr Surg 1998;14:391-7.

25 Leatherbarrow B, Inkster C, Ng S. Hydroxyapatite Implants. Ophthalmology 2003;110:1281-2.

26 Niechajev I. Porous polyethylene implants for nasal reconstuction: clinical and histologic studies. Aesth Plast Surg 1999;23:395-402.

27 Sevin K, Askar I, Saray A, et al. Exposure of high-density porous polyethylene (Medpor ${ }^{\circledR}$ ) used for contour restoration and treatment. Br J Oral Maxillofac Surg 2000;38:44-9.

\section{$\mathrm{ECHO}$}

\section{Blepharospasm and hemifacial spasm}

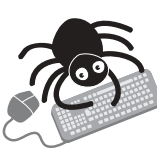

Please visit the British Journal of Ophthalmology website [www. bjophthalmol. com] for a link to the full text of this article.
B lepharospasm (BEB) is characterised by bilateral, and usually symmetrical and synchronous, contractions of the orbicularis oculi muscles, often with involvement of the frontalis and corrugator muscles. There may be associated dystonia of the lower face and jaw and of the neck muscles. In most cases no cause is found although BEB may be associated with lesions of the basal ganglia, brainstem, or thalamus. It is more common in women and may be familial. Eye disease and dental procedures may be precipitating factors. In hemifacial spasm (HFS) there are clonic or tonic contractions of muscles innervated by the facial nerve usually on one side, at least initially. In many cases there is vascular compression of the nerve at its exit from the skull. BEB and HFS appear to be distinct entities but a report from Singapore shows that some patients may suffer from both.

One hundred and sixty four consecutive patients with HFS attending a neurology (botulinum toxin treatment) clinic were compared with 501 non-neurological outpatient, age and sex matched controls. The mean age of HFS patients was 55 years ( $62 \%$ women) and of controls 51 years (61\% women). A diagnosis of coexisting BEB was made in 9 patients $(5.5 \%)$ in the HFS group but in none of the controls. Eight of the nine patients with both conditions were women. The BEB began after the HFS in six patients and before in one. The timing was not known for two patients. Magnetic resonance imaging and angiography in six of the nine patients showed vascular compression of the facial nerve on the same side as the HFS in five and no abnormality in one patient (whose HFS and BEB had followed Bell's palsy). In three patients HFS, but not BEB, was noted to persist in sleep.

Why some patients with HFS should develop BEB is unclear. It is suggested that facial weakness (spontaneous or induced by botulinum toxin treatment) in patients with HFS might cause a reduction in input to an inhibitory reflex affecting the muscles involved in BEB.

A Journal of Neurology, Neurosurgery, and Psychiatry 2004;75:494-496. 